Cite this: Phys. Chem. Chem. Phys., 2013, 15, 6673

Received 30th November 2012 Accepted 8th February 2013

DOI: $10.1039 / \mathrm{c3cp} 44295 k$

www.rsc.org/pccp

\section{Ultrafast photoinduced dynamics of halogenated cyclopentadienes: observation of geminate charge-transfer complexes in solution $\dagger$}

\author{
T. J. A. Wolf, ${ }^{* a}$ O. Schalk, ${ }^{\text {bcd }}$ R. Radloff, ${ }^{a}$ G. Wu, ${ }^{\text {be }}$ P. Lang, ${ }^{c}$ A. Stolow ${ }^{b}$ and \\ A.-N. Unterreiner ${ }^{* a}$
}

\begin{abstract}
The photoinduced dynamics of the fully halogenated cyclopentadienes $C_{5} \mathrm{Cl}_{6}$ and $\mathrm{C}_{5} \mathrm{Br}_{6}$ have been investigated in solution and gas phase by femtosecond time-resolved spectroscopy. Both in solution and in gas phase, homolytic dissociation into a halogen radical and a $\mathrm{C}_{5} \mathrm{X}_{5}(\mathrm{X}=\mathrm{Cl}, \mathrm{Br})$ radical was observed. In liquid phase, solvent-dependent formation of charge transfer complexes between geminate radicals was observed for the first time. These complexes were found to be surprisingly stable and offered the opportunity to follow the dynamics of specific radical pairs. In the case of $\mathrm{C}_{5} \mathrm{Cl}_{6}$ in trichloroethanol, a reaction of the chlorine radical with molecules from the solvent cage was observed.
\end{abstract}

\section{Introduction}

The kinetics and behavior of photo-generated radicals in solution are important issues in many fields of research, including atmospheric chemistry in clouds ${ }^{1}$ and photopolymerization. ${ }^{2}$ In particular, the behavior of halogen radicals originating from photodegradation of environmental pollutants in solution is a significant field of investigation. ${ }^{3,4}$ Bromine and chlorine radicals form charge-transfer (CT) complexes with many solvents and, therefore, exhibit characteristic absorption bands in the visible and the UV. ${ }^{5-14}$ These complexes are known to be very short-lived and to influence the reactivity of the radicals towards $\mathrm{H}$ abstraction. The charge-transfer absorption band can potentially act as a highly sensitive tool for investigating the formation and destruction of an individual complex. Therefore, we looked for a system which after photoinduced bond fission forms a CT complex itself.

\footnotetext{
${ }^{a}$ Institut für Physikalische Chemie and Center for Functional Nanostructures (CFN), Karlsruhe Institute of Technology (KIT), Fritz-Haber-Weg 2, 76131 Karlsruhe, Germany.E-mail: thomas.wolf@kit.edu, andreas.unterreiner@kit.edu; Fax: +49721608 46524; Tel: +4972160848022

${ }^{b}$ National Research Council, 100 Sussex Drive, Ottawa, K1A OR6, Canada

${ }^{c}$ Lehrstuhl für BioMolekulare Optik, Ludwig-Maximilians-Universität München, Oettingenstr. 67, 80538 München, Germany

${ }^{d}$ Stockholm University, AlbaNova University Center, SE-10691, Stockholm, Sweden

${ }^{e}$ State Key Laboratory of Molecular Reaction Dynamics, Dalian Institute of Chemical Physics, Chinese Academy of Sciences, Dalian, Liaoning 116023, P. R. China

† Electronic supplementary information (ESI) available. See DOI: 10.1039/ c3cp44295k
}

A suitable geminate CT complex has to be reasonably stabilized against geminate recombination or electron transfer, which can lead to ion pairs instead of radical pairs. Such an electron transfer, following homolytic bond dissociation, was recently shown to take place within $10 \mathrm{ps}$ in the photogeneration of the benzhydryl cation in solution. ${ }^{15,16}$ Additionally, geminate recombination was observed as a side reaction.

We were inspired by studies of Graf and Günthard, who observed photoinduced radical formation from fully chlorinated $\left(\mathrm{C}_{5} \mathrm{Cl}_{6}\right)$ and brominated cyclopentadienes $\left(\mathrm{C}_{5} \mathrm{Br}_{6}\right)$ via homolytic fission of a carbon-halogen bond at the $\mathrm{sp}^{3}$ position of the fivemembered ring after irradiation with a xenon lamp. ${ }^{17-19}$ Using EPR spectroscopy in solution, the resulting cyclopentadienyl radicals were observed to be planar and highly symmetrical $\left(D_{5 \mathrm{~h}}\right)$. When irradiating solutions of $\mathrm{C}_{5} \mathrm{Br}_{6}$ in a frozen solvent at liquid nitrogen temperatures, formation of a broad absorption band peaking at $480 \mathrm{~nm}$ was observed. Upon thawing the sample, the absorption disappeared. The absorption band was, therefore, assigned to geminate formation of $\mathrm{C}_{5} \mathrm{Br}_{5} \cdots \mathrm{Br}$ CT complex in the frozen solvent cage, and its destruction due to diffusion of the radicals upon thawing of the frozen solvent cage. However, in $\mathrm{C}_{5} \mathrm{Cl}_{6}$ no additional $\mathrm{CT}$ absorption band could be observed.

In comparison to e.g. benzhydryl chloride, where the photogenerated benzhydryl radical experiences a considerable stabilization via an electron transfer to the chlorine radical, and therewith oxidation to an aromatic electron configuration, ${ }^{15,16}$ the cyclopentadienyl radical can become aromatic only by reduction, i.e. acceptance of an electron. Since reduction by a halogen 
radical is rather unlikely, at least this geminate quenching channel can be ruled out.

The excited states of cyclopentadiene $\left(\mathrm{C}_{5} \mathrm{H}_{6}\right)$ were the subject of many experimental and theoretical investigations. ${ }^{20-30}$ The role of a low lying, spectroscopically dark excited singlet state with partially doubly excited character is a subject of current discussion. ${ }^{30}$ As it is known to undergo radiationless relaxation after photoexcitation within several tens of fs, the photolytic bond fission observed in the halogenated analogues can be expected to take place on a similar time scale. ${ }^{31}$

Therefore, $\mathrm{C}_{5} \mathrm{Cl}_{6}$ and $\mathrm{C}_{5} \mathrm{Br}_{6}$ are comparatively investigated by femtosecond transient absorption spectroscopy in the solvents cyclohexane, isopropanol, chloroform, and trichloroethanol, which are expected to exhibit a largely differing reactivity towards $\mathrm{H}$ abstraction by chlorine radicals. ${ }^{13}$

In many cases, it is difficult to disentangle excited state dynamics of the originally excited molecule from vibrational cooling in the ground state, additional ground state dynamics of photoproducts and their interaction with the solvent by solely considering photoinduced dynamics in solution. Hence, $\mathrm{C}_{5} \mathrm{Cl}_{6}$ and $\mathrm{C}_{5} \mathrm{Br}_{6}$ are also investigated by time-resolved photoelectron spectroscopy in the gas phase. Due to the missing solvent environment only purely excited state dynamics of the two compounds are expected to be observable in this case.

\section{Experimental}

\subsection{Sample preparation}

$\mathrm{C}_{5} \mathrm{Cl}_{6}$ (purity: 99\%) was purchased from Dr Ehrenstorfer ${ }^{39}$ and used without further purification. The synthesis of $\mathrm{C}_{5} \mathrm{Br}_{6}$ was adapted from the literature. ${ }^{40} \mathrm{~A}{ }^{13} \mathrm{C}-\mathrm{NMR}$ spectrum is depicted in Fig. S1 in the ESI. $\uparrow$ The purity is estimated to be $>95 \%$. Solvents were purchased from Sigma Aldrich and Carl Roth.

Steady state absorption spectra were obtained using a Varian Cary 500 spectrometer in fused silica cuvettes with an optical pathlength of $1 \mathrm{~mm}$.

\subsection{Femtosecond transient absorption spectroscopy in solution}

The details of the experimental setup are described elsewhere. ${ }^{41}$ Briefly, pump pulses at central wavelengths $\left(\lambda_{\mathrm{p}}\right)$ of $323 \mathrm{~nm}$ $\left(\mathrm{C}_{5} \mathrm{Cl}_{6}\right)$ and $350 \mathrm{~nm}\left(\mathrm{C}_{5} \mathrm{Br}_{6}\right)$ were produced using an UV-NOPA (ultraviolet noncollinear optical parametric amplifier). ${ }^{42,43}$ Probe pulses at wavelengths between $500 \mathrm{~nm}$ and $1050 \mathrm{~nm}$ at a polarisation plane at magic angle relative to the pump pulses were produced using a second NOPA. The pump intensity was kept below $4 \times 10^{8} \mathrm{~W} \mathrm{~cm}^{-2}$ to ensure that only small changes in optical density occur. The time resolution was measured by cross-correlation in the dyes BBQ $\left(\lambda_{\mathrm{p}}=323 \mathrm{~nm}\right)$ and stilbene $3\left(\lambda_{\mathrm{p}}=350 \mathrm{~nm}\right)$ to be always below 100 fs. Samples were measured at $20{ }^{\circ} \mathrm{C}$ in a flow cell system including a fused silica cuvette with an optical pathlength of $1 \mathrm{~mm}$. Rapid photodegradation of all samples was observed. To reduce effects of group velocity mismatch, the optical density of the solutions was kept above 3 at the respective excitation wavelengths, which resulted in a reduced effective optical pathlength for
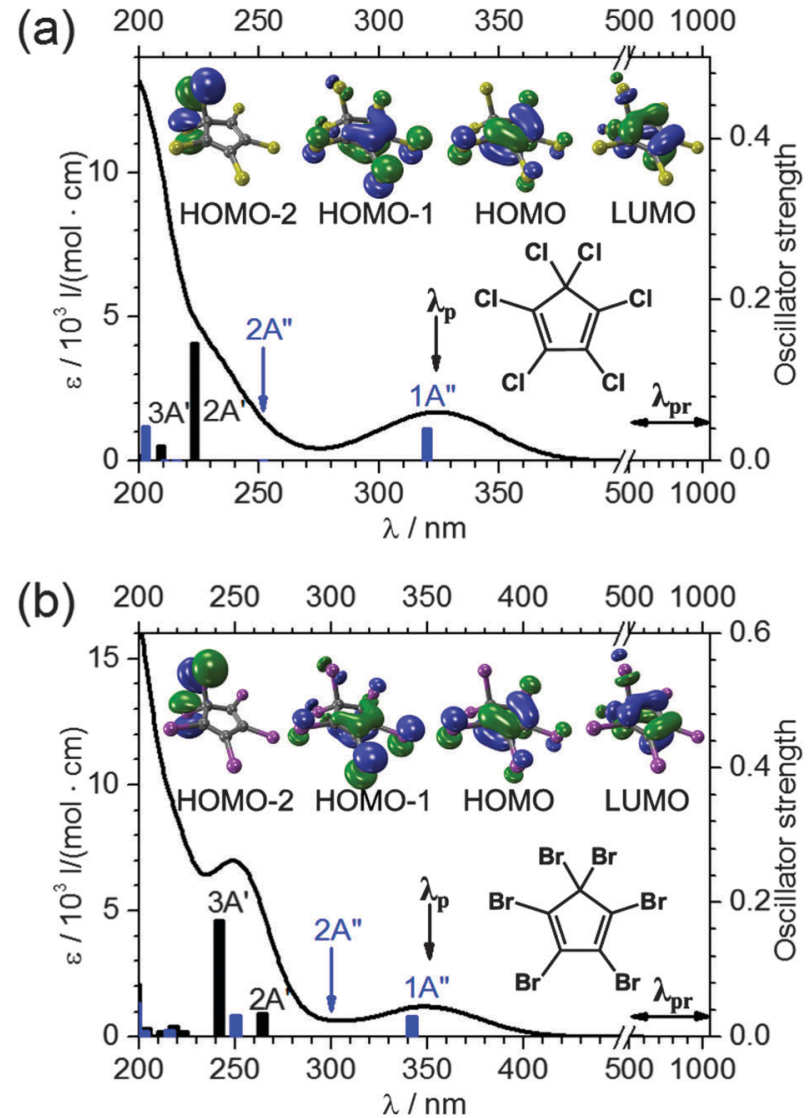

Fig. 1 Extinction coefficients of (a) $\mathrm{C}_{5} \mathrm{Cl}_{6}$ and (b) $\mathrm{C}_{5} \mathrm{Br}_{6}$ in cyclohexane solution together with singlet transitions calculated with CC2/aug-cc-pVDZ. Transitions to $A^{\prime}$ states are colored in black, excitations to $A^{\prime \prime}$ states in blue. Selected transitions are labeled. Furthermore, visualizations of the MOs, which are most relevant for the selected transitions, are inserted. Moreover, $\lambda_{\mathrm{p}}$ and the $\lambda_{\mathrm{pr}}$ range of the transient absorption experiments are marked.

the experiments. The concentrations were thus in the range of $2.5 \times 10^{-2} \mathrm{~mol} \mathrm{l}^{-1}$, depending on the extinction coefficients of $\mathrm{C}_{5} \mathrm{Cl}_{6}$ and $\mathrm{C}_{5} \mathrm{Br}_{6}$ at the respective $\lambda_{\mathrm{p}}$ (see Fig. 1).

\subsection{Time resolved photoelectron spectroscopy (TRPES)}

For time resolved experiments in the gas phase a photoelectron spectrometer was employed, consisting of a femtosecond laser system and a magnetic bottle time of flight spectrometer in combination with a supersonic molecular beam. The experimental setup is described in detail elsewhere. ${ }^{44}$ Briefly, pump pulses at $\lambda_{\mathrm{p}}=315 \mathrm{~nm}$ were generated by frequency quadrupling of the output of an optical parametric amplifier. Energies were $1.5 \mu \mathrm{J}$ (at $\lambda_{\mathrm{pr}}=267 \mathrm{~nm}$ ) and $1.6 \mu \mathrm{J}\left(\right.$ at $\left.\lambda_{\mathrm{pr}}=400 \mathrm{~nm}\right)$. For the probe wavelengths of $\lambda_{\mathrm{pr}}=266 \mathrm{~nm}(3.2 \mu \mathrm{J})$ and $400 \mathrm{~nm}(19 \mu \mathrm{J}) \mathrm{a}$ part of the laser output at $800 \mathrm{~nm}$ was frequency tripled or frequency doubled, respectively. The relative polarization of pump and probe pulses was rotated to magic angle. The pulses were collinearly focused into the interaction chamber of the photoelectron spectrometer. Photoelectron energies were calibrated by using the known photoelectron spectrum ${ }^{45}$ of $\mathrm{NO}$ and the cross correlation of pump and probe pulses was measured to be 140 fs by analyzing a nonresonant 3-photon $\left(\left[2,1^{\prime}\right]\right.$ or $\left.\left[1,2^{\prime}\right]\right)$ 
ionization peak of NO. In the interaction chamber a supersonic molecular beam generated by a $1 \mathrm{kHz}$ Even-Lavie valve with a $200 \mu \mathrm{m}$ diameter conical nozzle perpendicularly crossed the optical beam path. Helium was used as a carrier gas with a backing pressure of 3.8 bar. $\mathrm{C}_{5} \mathrm{Cl}_{6}$ was introduced into the body of the valve as a liquid, soaked into a filter paper. $\mathrm{C}_{5} \mathrm{Br}_{6}$ was introduced as a solid with additional filter paper. $\mathrm{C}_{5} \mathrm{Cl}_{6}$ was slightly heated to $40{ }^{\circ} \mathrm{C}, \mathrm{C}_{5} \mathrm{Br}_{6}$ to $80{ }^{\circ} \mathrm{C}$, to enhance the vapor pressure. To prevent condensation of the sample in the nozzle of the valve the frontplate of the valve was separately heated. Based on prior experience, the rotational and vibrational temperatures within the molecular beam can be assumed to exhibit values of $10-20 \mathrm{~K}$ and $100 \mathrm{~K}$, respectively.

\subsection{Theoretical methods}

Geometry optimizations, ground state, excitation energies and ionization potentials were calculated employing the TURBOMOLE V-6.3 program package. ${ }^{46}$ Geometry optimizations in the electronic ground state were performed with BP86/def2$\operatorname{SV}(\mathrm{P}) .{ }^{4-51}$ Ground state energies, first-order properties, and excitation energies were calculated with CC2/aug-cc-pVDZ ${ }^{52-55}$ as well as TDDFT/B3LYP/aug-cc-pVDZ. ${ }^{55-58}$ Ionization potentials were calculated with CCSD/def2-TZVP..$^{52-54,59}$ For CASSCF calculations, the COLUMBUS V5.9 (ref. 60-63) program package was employed.

\section{Results}

\subsection{Steady state spectroscopy}

The absorption spectra of $\mathrm{C}_{5} \mathrm{Cl}_{6}$ and $\mathrm{C}_{5} \mathrm{Br}_{6}$ in cyclohexane solution are depicted in Fig. 1 (a) and (b) together with calculated excitation spectra (CC2/aug-cc-pVDZ).

The ground state minimum geometries of $\mathrm{C}_{5} \mathrm{Cl}_{6}$ and $\mathrm{C}_{5} \mathrm{Br}_{6}$ both exhibit $C_{2 v}$ symmetry. However, for a nomenclature of the excited states, which is consistent with the photoproducts, all electronic states are labeled according to the $C_{\mathrm{s}}$ symmetry group. Transitions to selected excited states, which are important for the later discussion, are explicitly marked in Fig. 1. The MOs, which are most relevant for these transitions are additionally depicted. As could be expected from the employed method, excitation energies are slightly overestimated by the calculation.

The first absorption band of $\mathrm{C}_{5} \mathrm{Cl}_{6}$ at $\lambda=323 \mathrm{~nm}$ can be assigned to a $\pi \pi^{*}$ LUMO $\leftarrow$ HOMO transition (see Fig. 1 (a)) from the closed shell $1 \mathrm{~A}^{\prime}$ ground state to the lowest state with $\mathrm{A}^{\prime \prime}$ symmetry $\left(1 \mathrm{~A}^{\prime \prime}\right)$, which is in good agreement with the known excited states of $\mathrm{C}_{5} \mathrm{H}_{6} \cdot{ }^{21,23,25,27}$

The second excited state (labeled as $2 \mathrm{~A}^{\prime \prime}$ in Fig. 1 (a)) shows strong Rydberg character and is calculated to exhibit zero oscillator strength. Accordingly, it is not found in the experimental absorption spectrum. The $2 \mathrm{~A}^{\prime}$ state has mainly the character of a $\pi \pi^{*}$ LUMO $\leftarrow$ HOMO- 1 transition. This state is probably the analogue to the multiconfigurational $2 \mathrm{~A}_{1}$ state with additional doubly excited character, which was calculated to be the second excited state in $\mathrm{C}_{5} \mathrm{H}_{6}$. Due to the inability of CC2 to treat double excitations correctly, ${ }^{64}$ the calculated
Table 1 Properties of the employed solvents at $20^{\circ} \mathrm{C}$. If not otherwise indicated, dipole moments were calculated by CC2/aug-cc-pVDZ

\begin{tabular}{llll}
\hline Solvent & Density/g cm & Dipole moment/D & Viscosity/mPa s \\
\hline Cyclohexane & 0.78 (ref. 32) & 0.00 & 0.98 (ref. 32) \\
Isopropanol & 0.78 (ref. 33) & 1.61 & 2.5 (ref. 33) \\
Chloroform & 1.47 (ref. 34) & 1.04 (ref. 35) & 0.56 (ref. 34) \\
Trichloroethanol & 1.56 (ref. 36) & 2.04 (ref. 37) & 21 (ref. 38) \\
\hline
\end{tabular}

energy might be inaccurate. However, as will be discussed later, the role of this state is not significant for the observed dynamics.

The $3 \mathrm{~A}^{\prime}$ state has the character of a $n \pi^{*}$ excitation from the HOMO-2, which is a linear combination of two p-AOs of the chlorine atoms at the $\mathrm{sp}^{3}$ hybridized carbon atom, to the LUMO. Thus, the state has no analogue in $\mathrm{C}_{5} \mathrm{H}_{6}$. Furthermore, it can be expected to play an important role in the photoinduced bond fission, since one of the chlorine atoms is directly involved in the reaction. Moreover, the p-AO of the remaining chlorine atom comes in resonance with the $\pi$-system of the five-membered ring in the course of planarization of the $\mathrm{C}_{5} \mathrm{Cl}_{5}$ radical ( $D_{5 \mathrm{~h}}$ symmetry) after the bond fission.

As can be estimated from the spectra as well as the calculated excitation energies, bromination mainly leads to a considerable red shift of the absorption spectrum but not to a qualitative change in the excited state structure. Only the calculated states $2 \mathrm{~A}^{\prime}$ and $3 \mathrm{~A}^{\prime}$ interchange their character.

While different substituents at the carbon ring have considerable influence on the steady-state absorption spectra, the solvent plays a rather small role (for solvent properties see Table 1). Different solvents only lead to minor shifts in absorption maxima (for spectra in different solvents see Fig. S2 in the $\left.\mathrm{ESI}^{\dagger}\right)$.

\subsection{Transient absorption spectroscopy in solution}

3.2.1 $\mathbf{C}_{5} \mathbf{B r}_{6}$. The photoinduced dynamics leading from photoexcitation into the $1 \mathrm{~A}^{\prime \prime}$ state to formation of CT complexes were investigated by transient absorption (TA) spectroscopy. In the TA traces of $\mathrm{C}_{5} \mathrm{Br}_{6}$ the observed features are only slightly solvent-dependent. In Fig. 2 the transients taken in cyclohexane

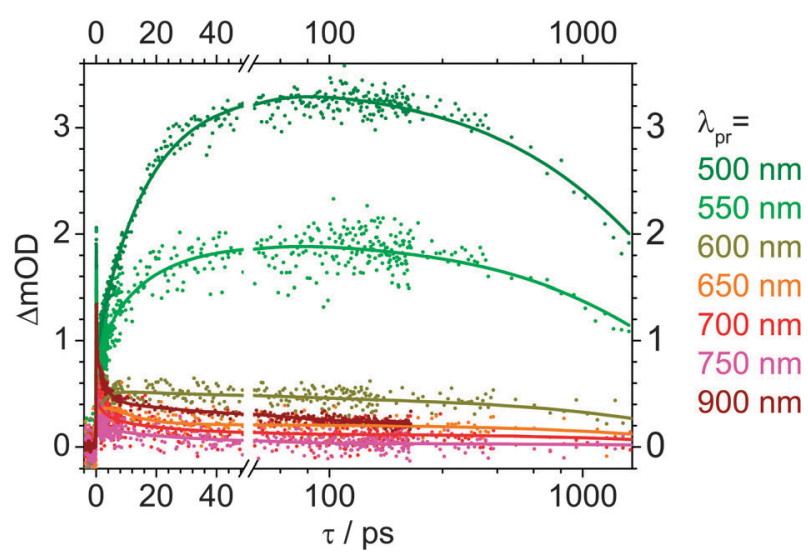

Fig. 2 Transient absorption traces (symbols) of $\mathrm{C}_{5} \mathrm{Br}_{6}$ in cyclohexane and global fit analysis (lines). Molecules are excited at $\lambda_{p}=350 \mathrm{~nm}$. 


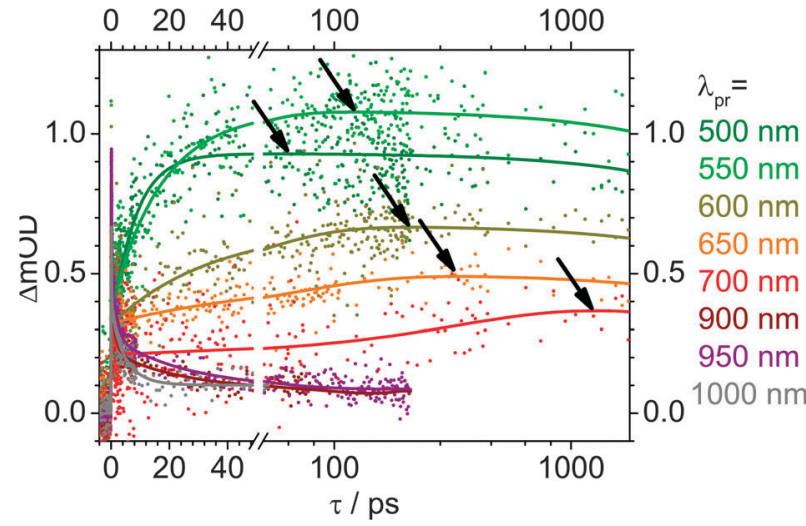

Fig. 3 Transient absorption traces (symbols) of $\mathrm{C}_{5} \mathrm{Br}_{6}$ in trichloroethanol and global fit analysis (lines). Molecules are excited at $\lambda_{p}=350 \mathrm{~nm}$ and probed at the $\lambda_{\mathrm{pr}}$ listed in the figure. The TA maximum shifts to longer delay times at longer $\lambda_{\mathrm{pr}}$ as indicated by the arrows. For transient spectra of $\mathrm{C}_{5} \mathrm{Br}_{6}$ in trichloroethanol constructed from the transient absorption traces, see Fig. $\mathrm{S} 6$ in the ESI. +

are shown. The TA intensity initially prepared at time zero can be attributed to absorption of the excited $1 \mathrm{~A}^{\prime \prime}$ state and decays within $<100$ fs irrespective of the employed $\lambda_{\text {pr }}$ or solvent. After the initial decay the evolution of TA is highly dependent on $\lambda_{\mathrm{pr}}$ : at short $\lambda_{\mathrm{pr}}$ (500-600 $\mathrm{nm}$ in the case of cyclohexane) the TA grows again within few tens of ps and decays on a time scale, which is beyond the experimentally accessible time window of $1.6 \mathrm{~ns}$. At long $\lambda_{\text {pr }}$ (650-900 nm for cyclohexane) the TA only decays to a value which is constant within the investigated time window. Obviously, in the spectral region between 500 and $600 \mathrm{~nm}$ the formation of a new absorption band can be observed. Its spectral signature fits well together with the earlier observed CT absorption bands of $\mathrm{C}_{5} \mathrm{Br}_{6}{ }^{18}$

In trichloroethanol, isopropanol and chloroform (see Fig. 3, Fig. S3 and S4 in the ESI $\dagger$ ) similar behavior is observed. However, the TA intensities at time zero and at the maxima of the forming absorption bands are lower and their spectral width is broadened in the chlorinated solvents. Thus, the solvent influence on the dynamics seems to be mostly of quantitative nature slightly influencing the transition strengths at the $\lambda_{\mathrm{pr}}$. The samples of $\mathrm{C}_{5} \mathrm{Br}_{6}$ in isopropanol and trichloroethanol also show slight qualitative differences, a red-shift of the maximum of the CT band with time delay, which is marked by arrows in Fig. 3 and Fig. S3 in the ESI. $\uparrow$ The appearance of the shift can be correlated with a higher polarity and viscosity of isopropanol and trichloroethanol in comparison to the other two solvents (see Table 1 for a list of solvent properties).

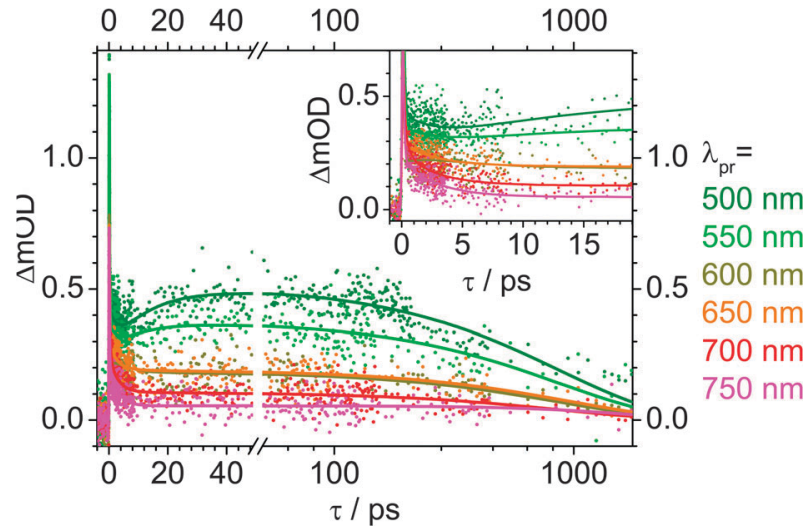

Fig. 4 Transient absorption traces (symbols) of $\mathrm{C}_{5} \mathrm{Cl}_{6}$ in isopropanol and global fit analysis (lines). Molecules are excited at $\lambda_{p}=323 \mathrm{~nm}$. Inserted is a more detailed plot of the transient absorption evolution within the first ps.

The experimental data are fitted with a 4-fold exponential function employing a Levenberg-Marquardt routine (see ESI, $\uparrow$ Section 3 for details), where the time constants $\tau_{1}, \tau_{2}$ and $\tau_{4}$ are adjusted globally for all TA traces in one specific solvent. $\tau_{3}$ was also adjusted globally for the solvents cyclohexane and chloroform. However, in the case of isopropanol and trichloroethanol $\tau_{3}$ had to be optimized for each $\lambda_{\mathrm{pr}}$ individually to model the observed spectral shift of the CT band maximum. The values of the time constants are listed in Table 2.

3.2.2 $\mathbf{C}_{5} \mathbf{C l}_{6}$. In comparison to $\mathrm{C}_{5} \mathrm{Br}_{6}$ the TA traces of $\mathrm{C}_{5} \mathrm{Cl}_{6}$ in isopropanol, cyclohexane, trichloroethanol, and chloroform (see Fig. 4-6 and Fig. S5 in the ESI, $\uparrow$ time constants are listed in Table 3) exhibit a more pronounced solvent dependence. The TA traces of $\mathrm{C}_{5} \mathrm{Cl}_{6}$ in isopropanol and chloroform (Fig. 4 and Fig. $\mathrm{S} 5$ in the ESI $\dagger$ ) show behavior which is qualitatively similar to the observations in $\mathrm{C}_{5} \mathrm{Br}_{6}$. This is in contradiction to earlier studies, where no CT band in the visible was observed. ${ }^{17}$ The major differences to the observations in $\mathrm{C}_{5} \mathrm{Br}_{6}$ are the time scales of rise and depletion of the TA at short $\lambda_{\mathrm{pr}}$.

Furthermore, TA traces in trichloroethanol (Fig. 6) exhibit a rise of TA at short $\lambda_{\text {pr }}$ on the ps timescale, but in the solvents isopropanol and chloroform the TA is quenched on the ps time scale. In this case a similar spectral shift of the transient TA maximum is found to that in the $\mathrm{TA}$ of $\mathrm{C}_{5} \mathrm{Br}_{6}$ in isopropanol and trichloroethanol.

In the TA traces of $\mathrm{C}_{5} \mathrm{Cl}_{6}$ in cyclohexane (Fig. 5) the initial TA intensity decays within $<100$ fs like in the other solvents (see the inset in Fig. 4). In sharp contrast to the other samples no rise of TA intensity at short $\lambda_{\mathrm{pr}}$ on the ps time scale is observed.

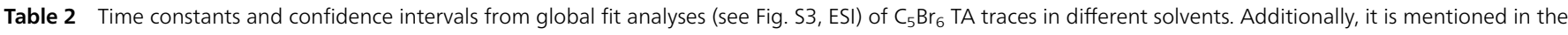

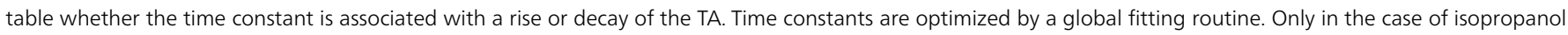
and trichloroethanol $\tau_{3}$ is optimized separately for each $\lambda_{\mathrm{pr}}$

\begin{tabular}{|c|c|c|c|c|}
\hline Solvent & $\tau_{1} /$ ps decay & $\tau_{2} /$ ps decay & $\tau_{3}$ range/ps rise & $\tau_{4} / \mathrm{ps}$ decay \\
\hline Cyclohexane & $0.07 \pm 0.02$ & $2.3 \pm 0.4$ & $17 \pm 2$ & $>2 \times 10^{3}$ \\
\hline Isopropanol & $0.07 \pm 0.03$ & $5 \pm 1$ & $(27 \pm 1)-(110 \pm 30)$ & $>2 \times 10^{3}$ \\
\hline Chloroform & $0.05 \pm 0.03$ & $9 \pm 3$ & $28 \pm 4$ & $>2 \times 10^{3}$ \\
\hline Trichloroethanol & $0.07 \pm 0.02$ & $1.6 \pm 0.4$ & $(8.0 \pm 0.8)-(400 \pm 100 \mathrm{fs})$ & $>2 \times 10^{3}$ \\
\hline
\end{tabular}




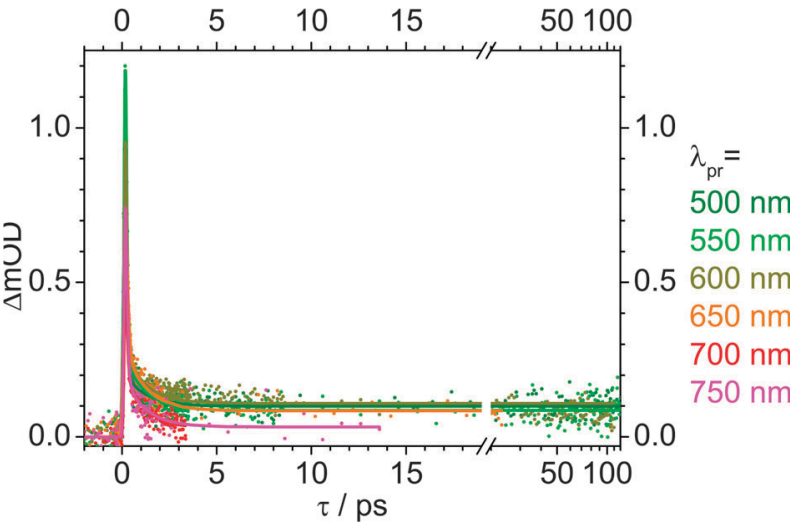

Fig. 5 Transient absorption traces (symbols) of $\mathrm{C}_{5} \mathrm{Cl}_{6}$ in cyclohexane and global fit analysis (lines). Molecules are excited at $\lambda_{p}=323 \mathrm{~nm}$.

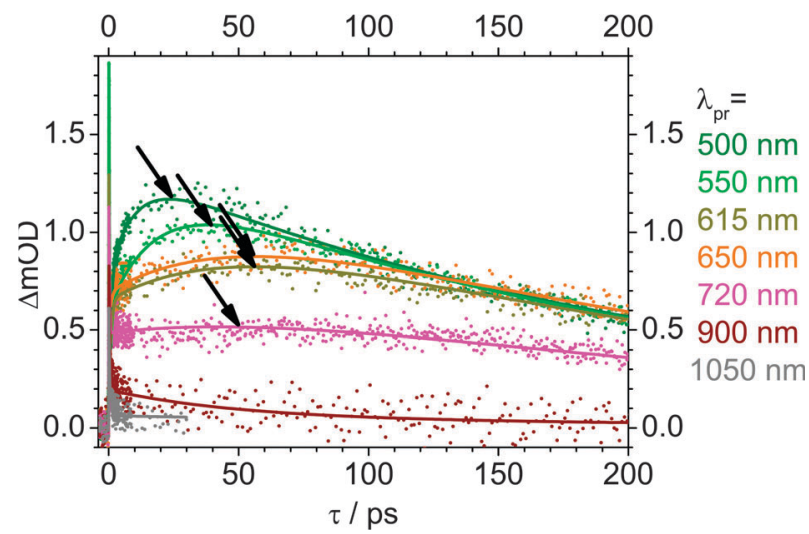

Fig. 6 Transient absorption traces (symbols) of $\mathrm{C}_{5} \mathrm{Cl}_{6}$ in trichloroethanol and global fit analysis (lines). Molecules are excited at $\lambda_{p}=323 \mathrm{~nm}$. The TA maximum shifts to longer delay times at longer $\lambda_{\mathrm{pr}}$ as indicated by the arrows.

\subsection{Time resolved photoelectron spectroscopy}

To disentangle excited state dynamics from ground state dynamics and solute-solvent interaction, the photoinduced dynamics of $\mathrm{C}_{5} \mathrm{Cl}_{6}$ and $\mathrm{C}_{5} \mathrm{Br}_{6}$ were investigated in the gas phase by time resolved photoelectron spectroscopy (TRPES). TRPES spectra of $\mathrm{C}_{5} \mathrm{Cl}_{6}\left(\lambda_{\mathrm{p}}=\right.$ $315 \mathrm{~nm}, \lambda_{\text {pr }}=267 \mathrm{~nm}$ and $400 \mathrm{~nm}$ ) are shown in Fig. 7 (a) and (b). For details on the data processing and the fitting procedure see ESI, $\uparrow$ Section 4. Two components can be distinguished in the TRPES spectrum at $\lambda_{\mathrm{pr}}=267 \mathrm{~nm}$ resulting from a $\left[1,2^{\prime}\right]$ ionization: around time zero we observe a very short lived and spectrally broad photoelectron band ranging from 0 to $3.5 \mathrm{eV}$. A second band, which is spectrally narrower $(0-1.3 \mathrm{eV})$, persists throughout the whole
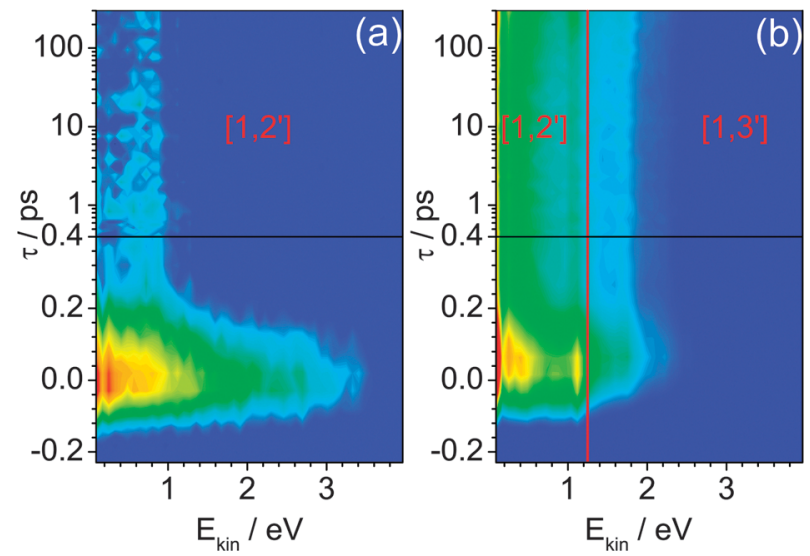

Fig. 7 Time resolved photoelectron spectra of $C_{5} \mathrm{Cl}_{6}$ at $\lambda_{\mathrm{p}}=315 \mathrm{~nm}$ and (a) $\lambda_{\mathrm{pr}}=$ $267 \mathrm{~nm}$ and $(\mathrm{b}) \lambda_{\mathrm{pr}}=400 \mathrm{~nm}$. In the latter spectrum the cutoff between $\left[1,2^{\prime}\right]$ and $\left[1,3^{\prime}\right]$ photon ionization at $1.26 \mathrm{eV}$ is inserted.

Table 4 Time constants and confidence intervals from global fit analyses of the TRPES spectra with doubly exponential decay functions (see ESI, Sections 4 and 5)

\begin{tabular}{llll}
\hline Sample & $\lambda_{\mathrm{pr}} / \mathrm{nm}$ & $\tau_{1} / \mathrm{ps}$ & $\tau_{2} / \mathrm{ps}$ \\
\hline $\mathrm{C}_{5} \mathrm{Cl}_{6}$ & 267 & $0.09 \pm 0.01$ & $>1 \times 10^{3}$ \\
$\mathrm{C}_{5} \mathrm{Cl}_{6}$ & 400 & $0.07 \pm 0.01$ & $>1 \times 10^{3}$ \\
$\mathrm{C}_{5} \mathrm{Br}_{6}$ & 400 & $0.15 \pm 0.01$ & $>1 \times 10^{3}$ \\
\hline
\end{tabular}

investigated time window of $300 \mathrm{ps}$. Both features are also found in the TRPES spectrum at $\lambda_{\mathrm{pr}}=400 \mathrm{~nm}$ (see Fig. 7 (b)). However, the spectral narrowing between short lived and persisting bands is not as pronounced as at $\lambda_{\mathrm{pr}}=267 \mathrm{~nm}$. In comparison to the data at $\lambda_{\mathrm{pr}}=267 \mathrm{~nm}$ the signature of the short lived band is more confined $(0-3 \mathrm{eV})$ and the signature of the persisting band more broadened (0-2.5 eV). Furthermore, both photoelectron bands observed at $\lambda_{\mathrm{pr}}=400 \mathrm{~nm}$ are more structured than the corresponding ones at $\lambda_{\mathrm{pr}}=267 \mathrm{~nm}$. The difference can be attributed to the energy cutoff between $\left[1,2^{\prime}\right]$ and $\left[1,3^{\prime}\right]$ photon ionization, which is also marked in the spectrum.

The spectra are fitted with two exponential functions. The resulting time constants are listed in Table 4 . In both data sets a very short time constant $\tau_{1}$ of $0.07-0.09 \mathrm{ps}$ is found. It is connected to the discussed spectral change within the first 100 fs after time zero. $\tau_{2}$ models the decay of the stable band and is therefore set to a high value, which cannot be specified in more detail by the available data.

Due to the small vapor pressure of $\mathrm{C}_{5} \mathrm{Br}_{6},{ }^{40}$ only TRPES spectra with a low count rate were recorded (see ESI, $†$ Section 5).

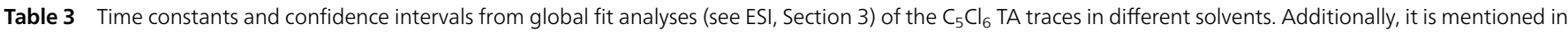

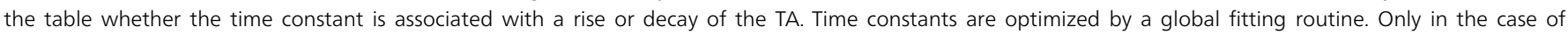
trichloroethanol $\tau_{3}$ is optimized separately for each $\lambda_{\mathrm{pr}}$

\begin{tabular}{|c|c|c|c|c|}
\hline Solvent & $\tau_{1} /$ ps decay & $\tau_{2} /$ ps decay & $\tau_{3}$ range/ps rise & $\tau_{4} /$ ps decay \\
\hline Cyclohexane & $0.07 \pm 0.03$ & $1.1 \pm 0.3$ & & $>2 \times 10^{3}$ \\
\hline Isopropanol & $0.09 \pm 0.01$ & $2.9 \pm 0.7$ & $12 \pm 2$ & $900 \pm 100$ \\
\hline Chloroform & $0.06 \pm 0.02$ & $2.1 \pm 0.8$ & $15 \pm 2$ & $>2 \times 10^{3}$ \\
\hline Trichloroethanol & $0.06 \pm 0.01$ & $1.7 \pm 0.1$ & $(12 \pm 1)-(150 \pm 30)$ & $220 \pm 2$ \\
\hline
\end{tabular}


Nevertheless, they evinced the same features as do the spectra of $\mathrm{C}_{5} \mathrm{Cl}_{6}$. The time constants resulting from a fit with two exponential functions are listed in Table 4 . In agreement with the findings for $\mathrm{C}_{5} \mathrm{Cl}_{6}$ a very short time constant $\tau_{1}=0.15 \mathrm{ps}$ and a time constant $\tau_{2}$ with a value beyond the experimentally accessible time scale are found.

\section{Discussion}

\subsection{Dynamics on the fs time scale}

The gas phase dynamics of both $\mathrm{C}_{5} \mathrm{Cl}_{6}$ and $\mathrm{C}_{5} \mathrm{Br}_{6}$ shows only one single concerted reaction step associated with $\tau_{1}$ and leads to a species, which is stable over the course of the experiment. From the knowledge of the photoinduced reactions in solution ${ }^{17,18}$ we assign the step to homolytic fission of a carbon-halogen bond at the $\mathrm{sp}^{3}$ position of the five-membered ring. The assignment is strongly supported by the absorption spectra of $\mathrm{C}_{5} \mathrm{Cl}_{5}$ and $\mathrm{C}_{5} \mathrm{Br}_{5}$ in solution, which exhibit - apart from temperature-dependent CT absorptions in the visible - further absorption bands at around $400 \mathrm{~nm} \cdot{ }^{17,18}$ Moreover, the calculated absorption spectrum of $\mathrm{C}_{5} \mathrm{Cl}_{5}$ (see ESI, $\uparrow$ Section 7) shows additional transitions with high oscillator strengths at around $267 \mathrm{~nm}$. A resonant photoionization at both wavelengths can explain the high intensities of the stable photoelectron bands in the TRPES spectra.

Furthermore, a large fraction of the photoenergy from the pump pulse $\left(\mathrm{C}_{5} \mathrm{Cl}_{6}: 3.84 \mathrm{eV}, \mathrm{C}_{5} \mathrm{Br}_{6}: 3.54 \mathrm{eV}\right)$ is converged to the dissociation reaction of $\mathrm{C}_{5} \mathrm{Cl}_{6}$ (typical $\mathrm{C}-\mathrm{X}$ dissociation energies: $\left.3.55 \mathrm{eV}(\mathrm{Cl}), 2.94 \mathrm{eV}(\mathrm{Br})^{65}\right)$ and the kinetic energy of the leaving chlorine atom. Hence, the photoproduct $\mathrm{C}_{5} \mathrm{Cl}_{5}$ can be expected to be only moderately vibrationally excited. This leads to a good Franck-Condon overlap between the $\mathrm{C}_{5} \mathrm{Cl}_{5}$ ground state and the lowest cationic state and, thereby, to an intense spectral signature as observed in the experimental data. ${ }^{66}$

In an alternative interpretation of the data one could assign the observed dynamics to relaxation into the ground state and the stable photoelectron band to ground state absorption of vibrationally "hot" molecules. This, however, is unlikely since such "hot" molecules would have a poor Franck-Condon overlap with the ionic manifold. Additionally, large amplitude motions of the carbon ring are expected to take place during the conversion into the ground state, which would lead e.g. to timedependent spectral shifts in the photoelectron bands. ${ }^{66}$ Since such an observation cannot be made in the TRPES spectra, we assign the stable feature of both $\mathrm{C}_{5} \mathrm{Cl}_{6}$ and $\mathrm{C}_{5} \mathrm{Br}_{6}$ to resonant ionization of $\mathrm{C}_{5} \mathrm{X}_{5}$ radicals. Accordingly, bond fission must be connected to $\tau_{1}$ and takes place on the sub-100 fs time scale.

Another fact supporting the assignment is the observed early dynamics of $\mathrm{C}_{5} \mathrm{X}_{6}$ in solution. The initial decay of TA after time zero takes place on the same time scale as the signal decay in the TRPES spectra. Thus, the time constants $\tau_{1}$ observed in gas phase and solution are likely to refer to the same processes. The dynamics following the initial decay can, therefore, be connected to processes involving the two radicals $\mathrm{C}_{5} \mathrm{X}_{5}$ and $\mathrm{X}$. This kind of process is typically not observable in gas phase, since a solvent cage keeping the two radical species together is missing.

\subsection{Experimental observation of the geminate CT complex generation}

As already mentioned, the rise of the $\mathrm{C}_{5} \mathrm{Br}_{6}$ TA-signal at short $\lambda_{\mathrm{pr}}$ fits well together with the known CT absorption bands in a frozen solvent resulting from a geminate $\left[\mathrm{C}_{5} \mathrm{Br}_{5} \cdots \mathrm{Br}\right]$ complex. ${ }^{18}$ Compared to the spectral signature observed here the earlier reported CT absorption band is slightly blue-shifted with the maximum at $480 \mathrm{~nm}$. The shift is most probably due to the difference in temperatures. The earlier observations were made at liquid nitrogen temperature, the present experiments at $20{ }^{\circ} \mathrm{C}$.

CT complexes of bromine radicals with different solvents are known to exhibit absorption bands in the UV. ${ }^{10}$ Hence, the absorption bands observed here cannot originate from interaction between the bromine radical and the solvent and have to be assigned to a geminate CT complex of the two radicals. Furthermore, in earlier experiments melting of the solvent led to disappearance of the absorption bands, ${ }^{18}$ which has to be due to dissociation of the CT complex. Other mechanisms like recombination and an electron transfer reaction cannot account for the disappearance, since the first takes place on shorter time scales ${ }^{14,67,68}$ and the latter is not favored as already discussed in the Introduction. Thus, the CT band intensity is a good tool for investigating the formation and dissociation of the geminate CT complex.

As opposed to $\mathrm{C}_{5} \mathrm{Br}_{6}$, geminate CT absorption bands in the visible originating from photolyzed $\mathrm{C}_{5} \mathrm{Cl}_{6}$ were not observed earlier. ${ }^{17,18}$ The solvent, which was employed at that time, was 3-methylpentane, an apolar hydrocarbon like the solvent cyclohexane. Therefore, these findings are in agreement with the present observations, since $\mathrm{C}_{5} \mathrm{Cl}_{6}$ does not exhibit a transient absorption band in the visible when dissolved in cyclohexane. Furthermore, CT complexes of $\mathrm{Cl}$ radicals with the solvent exhibit absorptions in the UV. ${ }^{7,11}$ Thus, the TA rise on the ps time scale can also be absorption of a geminate CT complex.

\subsection{Theoretical investigation of generation and character of CT complexes}

Possible structures of the photolyzed $\mathrm{C}_{5} \mathrm{X}_{6}$ were investigated by BP86/def2-SV(P). Due to disproportionately computational demand no solvent could be included into the calculations. Only one minimum with $C_{\mathrm{s}}$ symmetry could be found, where the leaving halogen atom is loosely bound to another halogen ring substituent. The halogen-halogen bond is thereby directed perpendicularly to the planar $\mathrm{C}_{5} \mathrm{X}_{5}$ ring system (see Fig. 8 (a)). The distance between the $\mathrm{Cl}(\mathrm{Br})$ atoms is $250 \mathrm{pm}(270 \mathrm{pm})$, which is considerably larger than the bond distance of $\mathrm{Cl}_{2}\left(\mathrm{Br}_{2}\right)$ (199 pm (229 pm)). ${ }^{65}$ The dissociation energy of the complex is estimated to be 28 (33) $\mathrm{kJ} \mathrm{mol}^{-1}$ (for details see Section 6 in the ESI $\dagger$ ). Additionally, TDDFT calculations reveal that these species also exhibit a very strong transition in a suitable spectral region to account for the experimentally observed absorption band (see Fig. 9). According to a Mulliken population analysis in the ground state, the loosely bound $\mathrm{Cl}(\mathrm{Br})$ exhibits a slightly negative charge of $-0.34(-0.25)$ and the nearest $\mathrm{Cl}(\mathrm{Br})$ ring substituent a positive charge of $0.21(0.60)$. Thus, it is most 
(a)

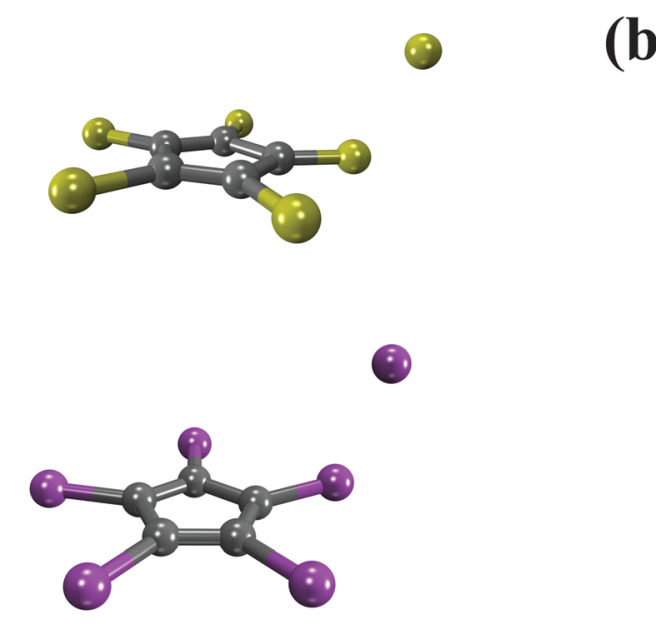

(b)

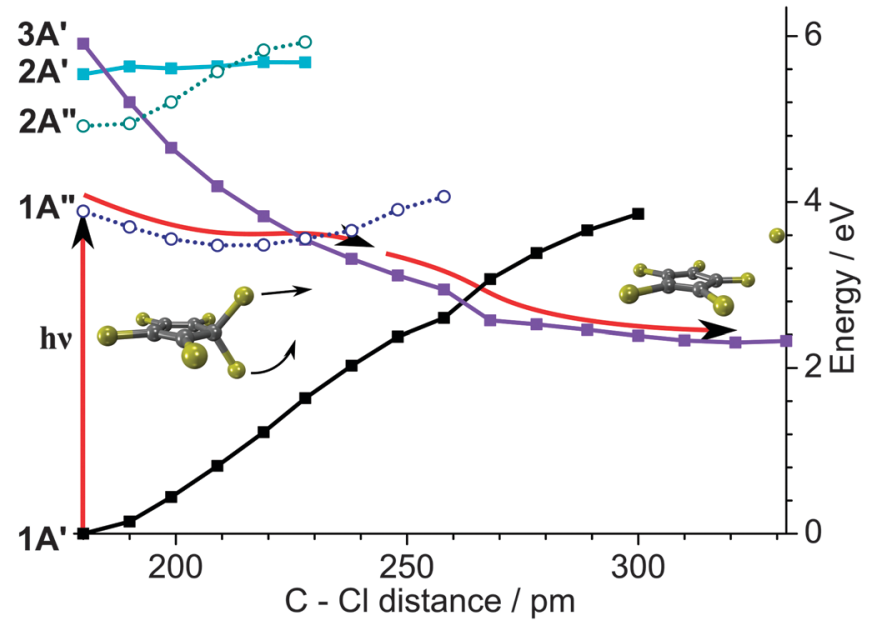

(c)
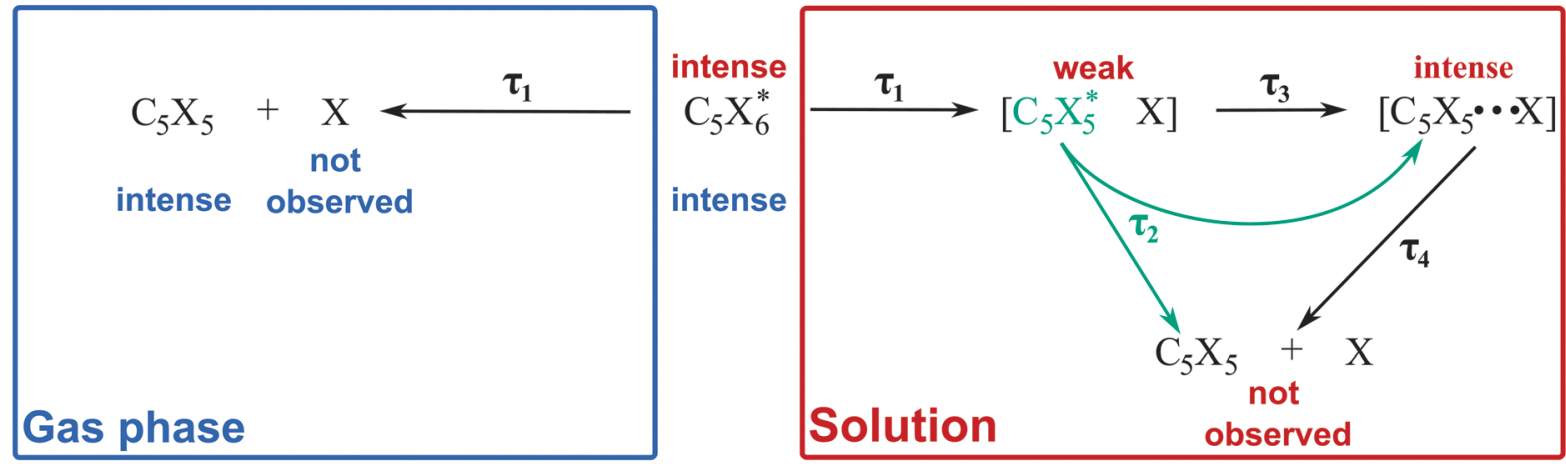

Fig. 8 (a) $\mathrm{CT}$ complex structures of $\mathrm{C}_{5} \mathrm{Cl}_{5} \ldots \mathrm{Cl}$ (above) and $\mathrm{C}_{5} \mathrm{Br}_{5} \ldots \mathrm{Br}$ (below) optimized by BP86/def2-SV(P). (b) Interpolated path between the minimum of $\mathrm{C}_{5} \mathrm{Cl} \mathrm{C}_{6}$ and the optimized CT complex minimum calculated at the CC2/aug-cc-pVDZ level of theory. The abscissa resembles the C-Cl bond dissociation coordinate. The states with $\mathrm{A}^{\prime}$ symmetry including the ground state are labeled by solid lines, the states with $\mathrm{A}^{\prime \prime}$ symmetry by dotted lines. The proposed relaxation pattern is marked by arrows. It includes the $1 \mathrm{~A}^{\prime}$ ground state (black), the $1 \mathrm{~A}^{\prime \prime}$ state (dark blue), which the molecule is excited into, and the $3 \mathrm{~A}^{\prime}$ state (violet). Intervening states $2 \mathrm{~A}^{\prime \prime}$ (green) and $2 \mathrm{~A}^{\prime}$ (light blue) are shown not to play a significant role. (c) Relaxation scheme for $\mathrm{C}_{5} \mathrm{Cl}_{6}$ and $\mathrm{C}_{5} \mathrm{Br}_{6}$ in the gas phase (blue) and in solution (red). The intensities of the generated species in the experimental data are additionally mentioned. After photoexcitation $C_{5} X_{6}{ }^{*}$ directly dissociates in the gas phase with a time constant $\tau_{1}$. In solution the same process is also found, but leads to formation of a geminate radical pair $\left[C_{5} X_{5}{ }^{*} X\right]$ in a joint solvent cage. Formation of the $C T$ complex $\left[C_{5} X_{5} \cdots X\right]$ associated with $\tau_{3}$ is accompanied by vibrational cooling of the $C_{5} X_{5}{ }^{*}$ radical fragment (green) associated with $\tau_{2}$. The $C T$ complex formation competes with escape of the halogen radical from the joint solvent cage, which cannot be directly observed in the experimental data. Quenching of the CT complex is connected to $\tau_{4}$.

probable that within the transition the CT takes place from the loosely bound halogen to the five-membered ring system.

An interpolated path between the $\mathrm{C}_{5} \mathrm{Cl}_{6}$ minimum and the minimum of the optimized species (see Fig. 8 (b)) at the CC2/aug-cc-pVDZ level of theory reveals a possible relaxation path in the direction of the $\mathrm{C}_{5} \mathrm{Cl}_{5} \cdots \mathrm{Cl}$ species. The abscissa resembles the $\mathrm{C}-\mathrm{Cl}$ bond dissociation coordinate. The states with $\mathrm{A}^{\prime}$ symmetry are labeled by solid lines, the states with $\mathrm{A}^{\prime \prime}$ symmetry by dotted lines. The discussion of the interpolated path can be reduced to the ground state of $\mathrm{C}_{5} \mathrm{Cl}_{6}$ and the excited states, which are marked in Fig. 1 (a): photoexcitation from the ground state (black) promotes the molecule to the first excited state with $\mathrm{A}^{\prime \prime}$-symmetry (blue). Planarization of the $\mathrm{C}_{5} \mathrm{Cl}_{5}$ ring and detachment of the $\mathrm{Cl}$ atom lead to a moderate lowering of the $1 \mathrm{~A}^{\prime \prime}$ state and a substantial lowering of the $3 \mathrm{~A}^{\prime}$ state resulting in a crossing. This state seems to be the ground state at the optimized $\mathrm{C}_{5} \mathrm{Cl}_{5} \cdots \mathrm{Cl}$ minimum. Thus, the speculations from Section 3.1 about the role of the $3 \mathrm{~A}^{\prime}$ state are strongly supported. Planarization of $\mathrm{C}_{5} \mathrm{Cl}_{5}$ and departure of the $\mathrm{Cl}$ atom lead to energy lowering of the LUMO due to interaction with the p-AO of the planarized $\mathrm{Cl}$ atom and to a rise of the energy of the HOMO-2 (see Fig. 1 (a)). An influence of the state, which is the ground state at the $C_{2 \mathrm{v}}$ minimum, as it is suggested by the projection of the interpolated path, is possible, but not definitive. Furthermore, the $2 \mathrm{~A}^{\prime}$ state can be neglected in the interpolation. An analogous interpolation was also done for $\mathrm{C}_{5} \mathrm{Br}_{6}$. The results are qualitatively comparable (see Fig. S12 in the ESI $\dagger$ ).

Since CC2 is known to poorly treat excited states with doubly excited character ${ }^{64}$ and the second excited state of $\mathrm{C}_{5} \mathrm{H}_{6}$ is known to have a multiconfigurational character with considerable contribution of a LUMO $\leftarrow$ HOMO double excitation, the CC2 results are re-evaluated by recalculating the same interpolated path for $\mathrm{C}_{5} \mathrm{Cl}_{6}$ employing SA-4-CASSCF(6,5)/6-31G $\mathrm{G}^{* 60-63}$ (see Fig. S11 and a description of the employed CAS in the ESI $\dagger$ ). Although the results are not quantitative, CASSCF is able to treat multiconfigurational states with doubly excited character qualitatively correctly. The results are in agreement with the CC2 results. An excited state comparable to the one in $\mathrm{C}_{5} \mathrm{H}_{6}$ is found, but it does not interfere with the three states 
considered above. As already discussed, the $3 \mathrm{~A}^{\prime}$ state has no analogue in $\mathrm{C}_{5} \mathrm{H}_{6}$. Therefore, the analogous CT complex structure cannot be optimized and this reaction channel is absent in $\mathrm{C}_{5} \mathrm{H}_{6}$.

\subsection{Mechanism of CT complex generation}

Despite the highly simplified picture presented by the interpolated path, it allows for an explanation of the experimentally observed excited state dynamics which we summarize in the reaction scheme in Fig. 8 (c): upon relaxation in the $1 \mathrm{~A}^{\prime \prime}$ state, photoexcited $\mathrm{C}_{5} \mathrm{X}_{6}$ reaches a surface crossing between $1 \mathrm{~A}^{\prime \prime}$ and $3 \mathrm{~A}^{\prime}$ leading to population transfer to $3 \mathrm{~A}^{\prime}$, which is associated with the time constant $\tau_{1}$. In the gas phase (left part of Fig. 8 (c)) leaving of the halogen atom is not hindered and the two radicals separate ballistically.

In solution (right part of Fig. 8 (c)) geminate radicals are generated in a joint solvent cage $\left(\left[\mathrm{C}_{5} \mathrm{X}_{5}{ }^{*} \mathrm{X}\right]\right)$ by the bond dissociation. Their spectral signatures are presumably governed by the absorption of the vibrationally excited $\mathrm{C}_{5} \mathrm{X}_{5}{ }^{*}$ radical (colored in green in Fig. 8 (c)). Its lowest absorption band peaks at around $400 \mathrm{~nm}^{17,18}$ outside of the investigated spectral window. Thus, the observed weak TA after the bond dissociation probably originates from the red-shifted absorption band of $\mathrm{C}_{5} \mathrm{X}_{5}{ }^{*}$ due to the vibrational excitation.

This is best observable in the case of $\mathrm{C}_{5} \mathrm{Cl}_{6}$ in cyclohexane, where the subsequent formation of a CT absorption band is missing. Accordingly, the chlorine radical is in this case able to escape from the joint solvent cage before the $\left[\mathrm{C}_{5} \mathrm{Cl}_{5} \cdots \mathrm{Cl}\right]$ complex can be formed, since photoinduced generation of $\mathrm{C}_{5} \mathrm{Cl}_{5}$ radicals was observed earlier by EPR spectroscopy in apolar solvents. ${ }^{17}$ Cage escape processes are known to take place on compatible time scales. ${ }^{14,67,68}$ Thus the decay of the weak signature connected to $\tau_{2}$ is most likely connected to vibrational cooling of $\mathrm{C}_{5} \mathrm{Cl}_{5}{ }^{*}$. However, a contribution of geminate recombination of the radicals cannot be fully excluded, since it typically takes place on an analogous time scale. ${ }^{12}$ However, if recombination takes place, it is definitely in competition with an escape of the halogen radical.

In the other samples the separation of the halogen radical from the $\mathrm{C}_{5} \mathrm{X}_{5}$ radical can be at least partially prevented by solvent caging. Thus, relaxation of the geminate radicals $\left[\mathrm{C}_{5} \mathrm{X}_{5}{ }^{*} \mathrm{X}\right]$ into the CT complex minimum $\left[\mathrm{C}_{5} \mathrm{X}_{5} \cdots \mathrm{X}\right]$ is possible. This relaxation is connected to a considerable growth in TA intensity in the blue part of the investigated spectral window, since it leads to formation of the CT absorption band. Accordingly, the process can be associated with $\tau_{3}$, which is represented by the TA growth in the fits.

Furthermore, in all samples and irrespective of the solvent, time constants $\tau_{2}$ with comparable spectral signatures and values were found (compare e.g. the inset in Fig. 4 with Fig. 5) and were assigned to the vibrational cooling of the $\mathrm{C}_{5} \mathrm{X}_{5}{ }^{*}$ fragment. However, it cannot be determined by the experimental data alone whether this indicates a competition between escape of the halogen atom from the solvent cage and formation of CT complexes in all investigated solvents.

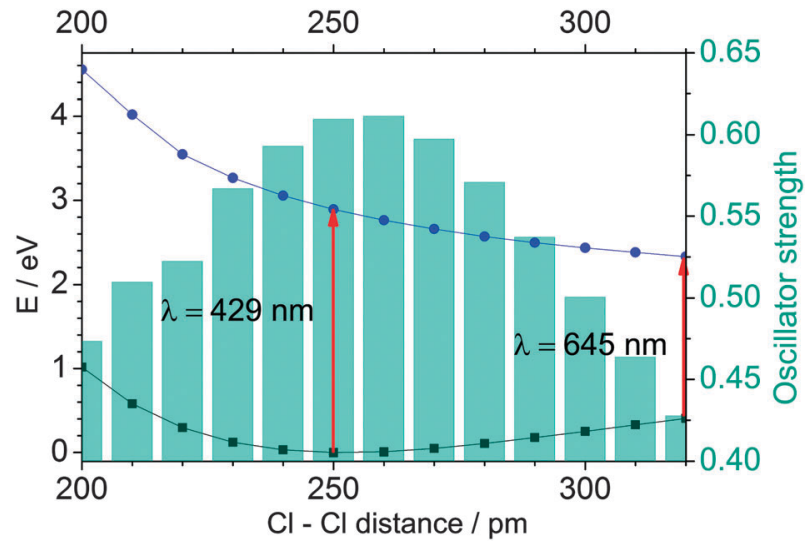

Fig. 9 Results from a coordinate scan of the $\mathrm{C}_{5} \mathrm{Cl}_{5} \ldots \mathrm{Cl}$ CT-complex dissociation by TDDFT/aug-cc-pVDZ. The dissociation coordinate is chosen to be the distance between the loosely bound chlorine atom and its nearest neighbor, a chlorine ring substituent. The black dots represent ground state energies of the CT complex, the blue dots represent energies of the lowest excited state with considerable oscillator strength. Additionally, the calculated oscillator strength of the transition between the two states dependent on the dissociation coordinate is depicted as bars. Enlargement of the bond distance leads to a considerable redshift and weakening of the calculated CT absorption band.

The observed CT complexes disappear on the time scale of $\tau_{4}$ (see Fig. 8 (c)). The nature of the underlying quenching process and the reasons for the highly solvent-dependent lifetimes are discussed in the following.

\subsection{Spectral shift of the CT absorption band}

The geminate CT absorption band can be expected to be sensitive even to small changes in the distance between the radicals. Therefore, we propose that the observed spectral shifts in the CT absorption band (see Fig. 3 and 6, and Fig. S3 in the ESI $\dagger$ ) are an indicator for a change in this distance. To support this interpretation, the dissociation coordinate of the $\mathrm{C}_{5} \mathrm{Cl}_{5} \cdots \mathrm{Cl}$ complex, i.e. the "bond" length between the $\mathrm{Cl}$ radical and the nearest $\mathrm{Cl}$ ring substituent, is scanned by TDDFT/B3LYP/aug-cc-pVDZ. TDDFT is not ideally suitable to describe excitation energies to CT states, ${ }^{69-71}$ but this flaw can partly be compensated by the use of hybrid functionals like B3LYP, as employed in the present case. ${ }^{72}$ In Fig. 9 the energies of the ground state and the excited state with the by far strongest oscillator strength are depicted as a function of the $\mathrm{Cl}-\mathrm{Cl}$ separation. Furthermore, the oscillator strengths for the transition at all calculated distances are shown as bars. Although the transition energies are slightly overestimated by the calculation, the plot gives a qualitative explanation for the observed spectral shift of the CT absorption band. Upon increasing the $\mathrm{Cl}-\mathrm{Cl}$ distance, the transition resonance shifts towards longer wavelengths and, simultaneously, the band intensity weakens. Thus, on the time scale of the spectral shift, motion of the halogen radical away from the cyclopentadienyl radical is observable.

\subsection{The fate of the CT complex}

The next question one might ask would be whether the motion of the halogen radical can also account for the quenching 
mechanism of the CT complex. In most cases, this can be ruled out by a comparison of the range of $\tau_{3}$ values with the observed $\tau_{4}$ values (see Tables 2 and 3). They differ by at least one order of magnitude. The only exception is $\mathrm{C}_{5} \mathrm{Cl}_{6}$ in trichloroethanol, where the values are comparable. This will be discussed in detail below.

A second issue to address is, if one of the two processes, spectral shift and CT complex quenching, exhibits a diffusive character. This can be decided by comparing their time scales to the time scale of diffusional motion. The time scale of the spectral shift can be quantified by the range of $\tau_{3}$ in Tables 2 and 3 . The time-dependence of the distance expectation value in diffusion is: ${ }^{73}$

$$
\left\langle d^{2}\right\rangle=2 D t
$$

By employing the Stokes-Einstein relation for the diffusion coefficient $D$ of a single radical species

$$
D=\frac{k_{\mathrm{B}} T}{6 \pi \eta r},
$$

one can evaluate the time, which is needed by the two radicals to diffuse an average distance $\sqrt{\left\langle d^{2}\right\rangle}$ by

$$
t=\frac{\left\langle d^{2}\right\rangle 6 \pi \eta r_{\mathrm{A}} r_{\mathrm{B}}}{2 k_{\mathrm{B}} T\left(r_{\mathrm{A}}+r_{\mathrm{B}}\right)} .
$$

The distance of diffusion is chosen to be the calculated equilibrium distance in the CT complex, i.e. an estimation is made about the time it takes for the radicals to achieve twice the bond distance $\left(250 \mathrm{pm}\left(\mathrm{C}_{5} \mathrm{Cl}_{5} \cdots \mathrm{Cl}\right)\right.$ vs. $\left.270 \mathrm{pm}\left(\mathrm{C}_{5} \mathrm{Br}_{5} \cdots \mathrm{Br}\right)\right)$. The radii of the radicals are estimated to be $r_{\mathrm{A}}=522 \mathrm{pm}\left(\mathrm{C}_{5} \mathrm{Cl}_{5}\right)$ and $560 \mathrm{pm}\left(\mathrm{C}_{5} \mathrm{Br}_{5}\right) \cdot r_{\mathrm{B}}$ is estimated to be $100 \mathrm{pm}(\mathrm{Cl})$ and $115 \mathrm{pm}$ $(\mathrm{Br})$, which are the covalent radii of the elements. ${ }^{65}$ Solvent viscosities are taken from Table 1. Chloroform exhibits the lowest viscosity ( $\eta=0.56 \mathrm{mPa}$ ) and trichloroethanol the highest $(\eta=21 \mathrm{mPa} \mathrm{s})$.

The time values calculated for $\mathrm{C}_{5} \mathrm{Cl}_{5} \cdots \mathrm{Cl}$ range between 7 and $260 \mathrm{ps}$ and between 11 and $410 \mathrm{ps}$ for $\mathrm{C}_{5} \mathrm{Br}_{5} \cdots \mathrm{Br}$, depending on the solvent viscosity, which is in reasonably good agreement with the range of $\tau_{3}$ values found in connection to the spectral shift. The shift could, therefore, be caused by a diffusional process. Comparison with the time scale of the CT band decay $\left(\tau_{4}\right)$ however shows a difference by an order of magnitude in most cases. A diffusive character of the quenching mechanism can, therefore, be excluded. It can be speculated that within the minimum of the CT complex diffusion is possible to a small extent, which then accounts for the observed spectral shift.

The comparison gives an additional hint for the nature of the CT complex. Apparently, its stabilization is not of purely sterical nature due to the solvent cage. As other groups found comparable time scales of CT absorption quenching in similar systems, ${ }^{14}$ the present case does not seem to be exceptional. As opposed to earlier investigations, the lifetime of the CT absorption is not due to a halogen radical forming transient CT species with solvent molecules during diffusion, but due to a considerably stronger interaction between two individual species.
The quenching, therefore, must be either due to a thermal cleavage reaction or due to direct reaction of the radicals constituting the CT complex with molecules from the solvent cage. It can only be speculated about the reactivity of the $\mathrm{C}_{5} \mathrm{X}_{5}$ radical. The most probable reaction is reduction to the anion, which is a stable aromatic. Due to a lower steric demand, however, the reactivity of the halogen radicals can be expected to have a higher influence on the quenching of the CT complex. $\mathrm{Cl}$ radicals are known to form $\mathrm{CT}$ complexes with halogenated solvents exhibiting absorption bands in the UV. ${ }^{7,11}$ Unlike $\mathrm{Br}$ radicals, which are known to be rather unreactive in solution and have lifetimes in the $\mu$ s range in many solvents, ${ }^{5,6,8-10,14}$ they undergo rapid reaction with solvent molecules under $\mathrm{H}$ abstraction. ${ }^{12,13,74}$ These reactions are assumed to be very fast in the case of aliphatic hydrocarbons and alcohols. For example, the time constant for the reaction between $\mathrm{Cl}$ and cyclohexane was measured to be $20 \mathrm{ps}^{74}$ Thus, the $\mathrm{C}_{5} \mathrm{Cl}_{5} \cdots \mathrm{Cl}$ CT complex can be quenched by direct reaction of $\mathrm{Cl}$ radicals with molecules from the solvent cage. However, in the case of $\mathrm{C}_{5} \mathrm{Cl}_{6}$ in cyclohexane the formation of a charge transfer complex is not observed, which prevents the reaction from being investigated at least in the visible spectral range. Hydrogen abstraction from isopropanol was observed to take place with a time constant of $12 \mathrm{ps}^{13}$ Comparison with the findings regarding the TA decay in isopropanol leads to the conclusion that direct reaction with the solvent cage cannot account for the TA quenching. The same also holds for chloroform. Thus, a thermal decomposition of the CT complex has to be assumed. Reactions of the halogen radicals following the decomposition do not seem to be observable in most solvents.

$\mathrm{C}_{5} \mathrm{Cl}_{6}$ in trichloroethanol, however, exhibits a TA decay, which is considerably faster than in the other solvents $\left(\tau_{4}=\right.$ $220 \mathrm{ps}$ ). The finding is in good agreement with the estimated diffusion time of 260 ps. Additionally, the spectral shift, which can be connected to a motion of the radicals away from each other, is on a similar time scale. Therefore, such a motion, which is only controlled by diffusion and eventually leads to quenching of the CT complex, can be assumed.

The question remains, why a diffusional quenching process is only possible in trichloroethanol. It seems rather improbable that the CT complex is destabilized to such great amount by bulk solvent properties, since the properties of isopropanol are generally similar (see Table 1). A possible reason for the behavior is a removal of the barrier by a direct hydrogen abstraction channel involving a molecule from the solvent cage. $\mathrm{H}$ abstraction could be facilitated for trichloroethanol in comparison to isopropanol by the electron withdrawing effect of the chlorine substitution.

\subsection{Conclusion}

The two systems $\mathrm{C}_{5} \mathrm{Cl}_{6}$ and $\mathrm{C}_{5} \mathrm{Br}_{6}$ have been investigated by femtosecond time-resolved pump-probe spectroscopy in the gas phase and various solvents. Upon irradiation they perform homolytic bond dissociation both in the gas phase and in solution within $\tau_{1}<100$ fs. Following the bond dissociation in solution, geminate formation of a CT complex is observed on 
the time scale of several ps. It thereby competes with escape of the halogen radical from the solvent cage and geminate recombination of the radicals taking place within few ps. The competition is thereby highly solvent dependent in the case of $\mathrm{C}_{5} \mathrm{Cl}_{6}$. The CT complexes are observed to be surprisingly stable in most solvents. In the solvent trichloroethanol the $\mathrm{C}_{5} \mathrm{Cl}_{5} \cdots \mathrm{Cl}$ CT complex is observed to be less stable by an order of magnitude than in the other solvents, which can be regarded as a hint for a direct $\mathrm{H}$ abstraction reaction of the $\mathrm{Cl}$ radical with a molecule from the solvent cage.

\section{Acknowledgements}

The authors acknowledge financial support provided by the Deutsche Forschungsgemeinschaft (DFG), the State of Baden-Württemberg and the Karlsruhe Institute of Technology (KIT) through the DFG-Center for Functional Nanostructures (CFN) within subproject $\mathrm{C}$ 3.02, the Fonds der Chemischen Industrie, NCERC and the DFG Cluster of Excellence: Munich Center for Advanced Photonics. O. S. thanks the Humboldt foundation for a Feodor-Lynen fellowship.

\section{References}

1 D. Vione, V. Maurino, C. Minero, E. Pelizzetti, M. A. J. Harrison, R.-I. Olariu and C. Arsene, Chem. Soc. Rev., 2006, 35, 441-453.

2 M. A. Tasdelen and Y. Yagci, Aust. J. Chem., 2011, 64, 982-991.

3 B. Halliwell, Mutat. Res., Genet. Toxicol. Environ. Mutagen., 1999, 443, 37.

4 S. Rayne, K. Forest and K. J. Friesen, Environ. Int., 2009, 35, 425-437.

5 N. Yamamoto, T. Kajikawa, H. Sato and H. Tsubomura, J. Am. Chem. Soc., 1969, 91, 265-267.

6 J. M. Bossy, R. E. Buehler and M. Ebert, J. Am. Chem. Soc., 1970, 92, 1099-1101.

7 J. E. Chateauneuf, Chem. Phys. Lett., 1989, 164, 577-580.

8 L. C. T. Shoute and P. Neta, J. Phys. Chem., 1990, 94, 2447-2453.

9 L. C. T. Shoute and P. Neta, J. Phys. Chem., 1990, 94, 7181-7184.

10 Z. B. Alfassi, R. E. Huie, J. P. Mittal, P. Neta and L. C. T. Shoute, J. Phys. Chem., 1993, 97, 9120-9123.

11 J. E. Chateauneuf, J. Org. Chem., 1999, 64, 1054-1055.

12 C. G. Elles, M. J. Cox, G. L. Barnes and F. F. Crim, J. Phys. Chem. A, 2004, 108, 10973-10979.

13 L. Sheps, A. C. Crowther, C. G. Elles and F. F. Crim, J. Phys. Chem. A, 2005, 109, 4296-4302.

14 S. L. Carrier, T. J. Preston, M. Dutta, A. C. Crowther and F. F. Crim, J. Phys. Chem. A, 2010, 114, 1548-1555.

15 B. P. Fingerhut, C. F. Sailer, J. Ammer, E. Riedle and R. de Vivie-Riedle, J. Phys. Chem. A, 2012, 116, 11064-11074.

16 J. Ammer, C. F. Sailer, E. Riedle and H. Mayr, J. Am. Chem. Soc., 2012, 134, 11481-11494.
17 F. Graf and H. H. Günthard, Chem. Phys. Lett., 1970, 7, 25-28.

18 F. Graf and H. H. Günthard, Chem. Phys. Lett., 1971, 8, 395-398.

19 P. Bachmann, F. Graf and H. Günthard, Chem. Phys., 1975, 9, 41-56.

20 W. Fuß, W. E. Schmid and S. Trushin, Chem. Phys., 2005, 316, 225-234.

21 T. Kovar and H. Lischka, J. Mol. Struct., 1994, 303, 71-82.

22 F. Rudakov and P. M. Weber, Chem. Phys. Lett., 2009, 470, 187-190.

23 O. Schalk, A. E. Boguslavskiy and A. Stolow, J. Phys. Chem. A, 2010, 114, 4058-4064.

24 F. Rudakov and P. M. Weber, J. Phys. Chem. A, 2010, 114, 4501-4506.

25 M. Z. Zgierski and F. Zerbetto, Chem. Phys. Lett., 1991, 179, 131-136.

26 L. Serrano-Andres, M. Merchan, I. Nebot-Gil, B. O. Roos and M. Fulscher, J. Am. Chem. Soc., 1993, 115, 6184-6197.

27 M. Z. Zgierski and F. Zerbetto, J. Chem. Phys., 1993, 99, 3721-3729.

28 H. Nakano, T. Tsuneda, T. Hashimoto and K. Hirao, J. Chem. Phys., 1996, 104, 2312-2320.

29 J. Wan, M. Ehara, M. Hada and H. Nakatsuji, J. Chem. Phys., 2000, 113, 5245-5252.

30 T. S. Kuhlman, W. J. Glover, T. Mori, K. B. Møller and T. Martinez, Faraday Discuss., 2012, 157, 193-212.

31 O. Schalk and A.-N. Unterreiner, J. Phys. Chem. A, 2007, 111, 3231-3240.

32 Safety data sheet of cyclohexane, downloaded from Carl Roth 2012.07.18.

33 Safety data sheet of isopropanol, downloaded from Carl Roth 2012.07.18.

34 Safety data sheet of chloroform, downloaded from Carl Roth 2012.07.18.

35 E. S. Snow, F. K. Perkins, E. J. Houser, S. C. Badescu and T. L. Reinecke, Science, 2005, 307, 1942-1945.

36 Safety data sheet of trichloroethanol, downloaded from Sigma Aldrich 2012.07.18.

37 S. S. Krishnamurthy and S. Soundararajan, J. Phys. Chem., 1969, 73, 4036-4039.

38 N. S. Angerman and R. B. Jordan, J. Chem. Phys., 1971, 54, 837-843.

39 http://www.analytical standards.com.

40 F. Strauss, L. Kollek and W. Heyn, Ber. Dtsch. Chem. Ges. B, 1930, 63, 1868-1885.

41 T. J. A. Wolf, D. Voll, C. Barner-Kowollik and A.-N. Unterreiner, Macromolecules, 2012, 45, 2257-2266.

42 E. Riedle, M. Beutter, S. Lochbrunner, J. Piel, S. Schenkl, S. Spörlein and W. Zinth, Appl. Phys. B: Lasers Opt., 2000, 71, 457-465.

43 I. Z. Kozma, P. Baum, S. Lochbrunner and E. Riedle, Opt. Express, 2003, 11, 3110-3115.

44 S. Lochbrunner, J. J. Larsen, J. P. Shaffer, M. Schmitt, T. Schultz, J. G. Underwood and A. Stolow, J. Electron Spectrosc. Relat. Phenom., 2000, 112, 183-198. 
45 G. K. Jarvis, M. Evans, C. Y. Ng and K. Mitsuke, J. Chem. Phys., 1999, 111, 3058-3069.

46 R. Ahlrichs, M. Bär, M. Häser, H. Horn and C. Kölmel, Chem. Phys. Lett., 1989, 162, 165-169.

47 O. Treutler and R. Ahlrichs, J. Chem. Phys., 1995, 102, 346-354.

48 K. Eichkorn, O. Treutler, H. Öhm, M. Häser and R. Ahlrichs, Chem. Phys. Lett., 1995, 240, 283-290.

49 K. Eichkorn, O. Treutler, H. Öhm, M. Häser and R. Ahlrichs, Chem. Phys. Lett., 1995, 242, 652-660.

50 F. Weigend, Phys. Chem. Chem. Phys., 2006, 8, 1057-1065.

51 A. Schäfer, H. Horn and R. Ahlrichs, J. Chem. Phys., 1992, 97, 2571-2577.

52 C. Hättig and F. Weigend, J. Chem. Phys., 2000, 113, 5154-5161.

53 C. Hättig and A. Köhn, J. Chem. Phys., 2002, 117, 6939-6951.

54 A. Köhn and C. Hättig, J. Chem. Phys., 2003, 119, 5021-5036.

55 R. A. Kendall, T. H. Dunning and R. J. Harrison, J. Chem. Phys., 1992, 96, 6796-6806.

56 F. Furche and D. Rappoport, Computational and Theoretical Chemistry, Elsevier, Amsterdam, 2005, vol. 16.

57 R. Bauernschmitt and R. Ahlrichs, Chem. Phys. Lett., 1996, 256, 454-464.

58 R. Bauernschmitt and R. Ahlrichs, J. Chem. Phys., 1996, 104, 9047-9052.

59 F. Weigend and R. Ahlrichs, Phys. Chem. Chem. Phys., 2005, 7, 3297-3305.

60 H. Lischka, R. Shepard, F. B. Brown and I. Shavitt, Int. J. Quantum Chem., 1981, 20, 91-100.
61 R. Shepard, I. Shavitt, R. M. Pitzer, D. C. Comeau, M. Pepper, H. Lischka, P. G. Szalay, R. Ahlrichs, F. B. Brown and J.-G. Zhao, Int. J. Quantum Chem., 1988, 34, 149-165.

62 H. Lischka, R. Shepard, R. M. Pitzer, I. Shavitt, M. Dallos, T. Muller, P. G. Szalay, M. Seth, G. S. Kedziora, S. Yabushita and Z. Zhang, Phys. Chem. Chem. Phys., 2001, 3, 664-673.

63 H. Lischka, T. Müller, P. G. Szalay, I. Shavitt, R. M. Pitzer and R. Shepard, WIREs Comput. Mol. Sci., 2011, 1, 191-199.

64 M. Schreiber, M. R. Silva-Junior, S. P. A. Sauer and W. Thiel, J. Chem. Phys., 2008, 128, 134110-134125.

65 CRC Handbook of Chemistry and Physics, ed. W. M. Haynes, CRC Press, Boca Raton, FL, 92nd edn, 2011-2012.

66 O. Schalk, A. E. Boguslavskiy, A. Stolow and M. S. Schuurman, J. Am. Chem. Soc., 2011, 133, 16451-16458.

67 I. Benjamin, J. Chem. Phys., 1995, 103, 2459-2471.

68 I. Chorny, J. Vieceli and I. Benjamin, J. Chem. Phys., 2002, 116, 8930-8937.

69 M. E. Casida, F. Gutierrez, J. Guan, F.-X. Gadea, D. Salahub and J.-P. Daudey, J. Chem. Phys., 2000, 113, 7062-7071.

70 A. Dreuw, J. L. Weisman and M. Head-Gordon, J. Chem. Phys., 2003, 119, 2943-2946.

71 K. Sadeghian and M. Schütz, J. Am. Chem. Soc., 2007, 129, 4068-4074.

72 D. Rappoport and F. Furche, J. Am. Chem. Soc., 2004, 126, 1277-1284.

73 H. J. V. Tyrrell and K. R. Harris, Diffusion in liquids, Butterworths, London, 1984.

74 D. Raftery, M. Iannone, C. Phillips and R. Hochstrasser, Chem. Phys. Lett., 1993, 201, 513-520. 